\title{
Large-amplitude internal waves sustain coral health during thermal stress
}

\author{
Gertraud M. Schmidt ${ }^{1}$ - Marlene Wall ${ }^{1,2} \cdot$ Marc Taylor $^{3} \cdot$ Carin Jantzen $^{1,4}$. \\ Claudio Richter ${ }^{1,5}$
}

Received: 17 June 2015/Accepted: 5 April 2016/Published online: 18 April 2016

(c) The Author(s) 2016. This article is published with open access at Springerlink.com

\begin{abstract}
Ocean warming is a major threat for coral reefs causing widespread coral bleaching and mortality. Potential refugia are thus crucial for coral survival. Exposure to large-amplitude internal waves (LAIW) mitigated heat stress and ensured coral survival and recovery during and after an extreme heat anomaly. The physiological status of two common corals, Porites lutea and Pocillopora meandrina, was monitored in host and symbiont traits, in response to LAIW-exposure throughout the unprecedented 2010 heat anomaly in the Andaman Sea. LAIW-exposed corals of both species survived and recovered, while LAIW-sheltered corals suffered partial and total mortality in $P$. lutea and $P$. meandrina, respectively. LAIW are ubiquitous in the tropics and potentially generate coral refuge areas. As thermal stress to corals is expected to
\end{abstract}

Communicated by Biology Editor Dr. Line K. Bay

Electronic supplementary material The online version of this article (doi:10.1007/s00338-016-1450-z) contains supplementary material, which is available to authorized users.

Gertraud M. Schmidt

gertraud.schmidt@awi.de

Marlene Wall

mwall@geomar.de

Marc Taylor

marc.taylor@thuenen.de

Carin Jantzen

carin.jantzen@gmx.net

Claudio Richter

claudio.richter@awi.de

1 Alfred Wegener Institute, Helmholtz Center for Polar and Marine Research, Am Alten Hafen 26, 27568 Bremerhaven, Germany increase in a warming ocean, the mechanisms linking coral bleaching to ocean dynamics will be crucial to predict coral survival on a warming planet.

Keywords Ocean warming $\cdot$ Coral bleaching $\cdot$ Coral recovery $\cdot$ Large-amplitude internal waves $\cdot$ Cooling

\section{Introduction}

Global warming is the key cause of extensive coral bleaching (Brown et al. 2000; Hoegh-Guldberg et al. 2007). For most corals living in obligate endosymbiosis with unicellular dinoflagellate algae (genus Symbiodinium, or zooxanthellae), thermal stress can lead to the disruption of the photosymbiosis, temporary or permanent loss of microalgae from coral tissues and bleaching (Glynn 1996). As the main source of energy for reef-building corals is photosynthesis by Symbiodinium (e.g., Muscatine 1990), photoinhibition and symbiont loss (Lesser 2006) can have a severe impact on the energy supply (Muscatine 1990;

2 GEOMAR, Helmholtz Center for Ocean Research, Marine Geosystems, Wischhofstraße 1-3, 24148 Kiel, Germany

3 Thünen Institute of Sea Fisheries, Palmaille 9, 22767 Hamburg, Germany

4 SECORE Foundation Media and Communications, Höhenstraße 23, 65520 Bad Camberg, Germany

5 University of Bremen, Bremen, Germany 
Grottoli et al. 2004), biomass (Fitt et al. 2009), and calcification (Moya et al. 2006) of the coral. Coral mortality can result if zooxanthellae numbers are not restored or if the coral is unable to meet its energy demands from other sources, i.e., stored energy reserves (Grottoli et al. 2004) or heterotrophy (Grottoli et al. 2006; Connolly et al. 2012). Coral recovery after disturbance depends on physiological and genetic factors, environmental factors and time (Grottoli et al. 2006). Incomplete recovery before the next disturbance increases the risk of losing bleaching-susceptible corals, depressing coral biodiversity (McClanahan et al. 2007b). Reports of coral bleaching have increased in the last three decades with progressively shorter recovery phases after the 1998 global mass-bleaching event described by Hoegh-Guldberg et al. (2007). Predictions based on climate models and thermal tolerances and regional bleaching thresholds of corals suggest regular widespread bleaching and coral mortality will occur over the next decades (van Hooidonk et al. 2013).

The predicted demise of coral reefs underscores the importance of refugia (Glynn 1996; Riegl and Piller 2003) where corals have a higher chance of survival under generally raised ocean temperatures (van Hooidonk et al. 2013 and literature therein). Upwelling regions have been invoked as potential refugia where cool subsurface water reaching the surface may alleviate heating and promote the recovery of corals after heat stress (cf. Riegl and Piller 2003). However, wind-driven upwelling is often seasonal and out of phase with heat anomalies which often coincide with extended slack periods (e.g., Brown et al. 2000).

Internal waves can mix deep sub-pycnocline waters into shallow reef areas at tidal and higher frequencies (Leichter et al. 2005; Schmidt et al. 2012; Wall et al. 2012). Although they are ubiquitous in stratified tropical regions with strong tidal flows (Jackson 2007), their role in shaping reef communities is largely unexplored. The Andaman Sea, in the eastern Indian Ocean, harbours internal waves of exceptional amplitude $(80 \mathrm{~m})$. These large-amplitude internal waves (LAIW) originate along the Andaman Nicobar Islands and northwest of Sumatra and travel in packages as $\mathrm{V}$-shaped depressions of the pycnocline across the Andaman basin (Osborne and Burch 1980). Near the Thai-Malaysian continental shelf they interact with the bottom to transform into waves of elevation and break, spilling pulses of deep water onto the shelf (Vlasenko and Stashchuk 2007). The Similan Islands located in the swash zone of breaking LAIW receive frequent (several events per hour) and sudden (within minutes) drops in temperature accompanied by concomitant increases in inorganic nutrients (Schmidt et al. 2012) and plankton supply (Roder et al. 2010) on their western sides. The eastern sides are largely protected from LAIW resulting in largely constant temperature conditions and comparatively low nutrient and plankton supplies (Table 1). LAIW vary seasonally as a function of thermocline depth, with a peak in March at the height of the calm northeast monsoon (January until May; Schmidt et al. 2012). During the stormy southwest monsoon (June through October), LAIW are weaker. During this period wind mixing, swell and sediment resuspension are the main disturbances affecting corals (Wall et al. 2012; Table 1). However, because both LAIW and the monsoon act from the same westerly side, differentiation between LAIW and monsoon effects requires a spatio-temporal (rather than a purely spatial) approach.

The Andaman Sea experienced an exceptional thermal anomaly in 2010. Monthly mean temperatures exceeded the NOAA coral bleaching threshold for the area $\left(30.62{ }^{\circ} \mathrm{C}\right.$ ) over a period of 3 months (April to June; Wall et al. 2014). Severe bleaching and up to $80 \%$ mortality marked the 2010 event as the strongest so far on record (Brown and Phongsuwan 2012). In spite of the severity of the 2010 event, some reefs were less affected, allegedly due to stronger currents or the presence of cold water (Phongsuwan and Chansang 2012) as suggested by earlier observations of high temperature variability in Indian Ocean (Sheppard 2009) and Andaman Sea coral reefs (Roder et al. 2010, 2011; Schmidt et al. 2012; Wall et al. 2012). Wall et al. (2014), linking coral community data on bleaching and mortality with heat stress and LAIW, suggested that LAIW benefit corals under thermal stress: they observed that LAIW-exposed coral communities across the Thai Andaman shelf showed reduced bleaching and mortality, while LAIW-sheltered communities suffered intense bleaching and total mortality. Although the study highlighted the importance of species composition, notably the proportion of bleaching-susceptible versus bleaching-resistant species, a mechanistic understanding of the bleaching and mortality response at the organism level is still lacking.

This field study assesses the relative roles of LAIW and the monsoon on coral bleaching, recovery and mortality. We compared the bleaching response and survival of LAIW-exposed and LAIW-sheltered representatives of a bleaching-susceptible and bleaching-resistant coral species before, during and after the 2010 Andaman Sea thermal anomaly. We used the natural setting of the Similan Islands to test to what extent cooling and advection due to LAIW affected the physiology of the corals and their algal symbionts and to identify possible differences between the heat resistant and sensitive species. The massive coral Porites lutea Milne Edwards and Haime, 1851 and the branched Pocillopora meandrina Dana, 1846 were chosen as models, as they are common along the $\mathrm{W}$ and $\mathrm{E}$ sides of the Similans (Schmidt et al. 2012) and show different sensitivities to heat stress (Hoegh-Guldberg and Salvat 1995; Fitt et al. 2009). 
Table 1 Descriptive presentation of environmental conditions prevailing on eastern and western sides of the Similan Islands during the northeast (January until May) and south-west (June through October) monsoons

\begin{tabular}{lllll}
\hline Environmental factor & Side & $\begin{array}{l}\text { North-east } \\
\text { monsoon }\end{array}$ & $\begin{array}{l}\text { South-west } \\
\text { monsoon }\end{array}$ & References \\
\hline Temperature fluctuations & West & $\mathrm{H}$ & $\mathrm{I}$ & Schmidt et al. (2012), Wall et al. (2012) \\
& East & $\mathrm{L}$ & $\mathrm{L}$ & Roder et al. (2010), Wall et al. (2012) \\
Water movement & West & $\mathrm{H}$ & $\mathrm{H}$ & L \\
& East & $\mathrm{L}$ & $\mathrm{H}$ & Wall et al. (2012) \\
Sedimentation rate & West & $\mathrm{L}$ & $\mathrm{L}$ & Schmidt et al. (2012), Jantzen et al. (2013) \\
& East & $\mathrm{L}$ & - & Schmidt et al. (2012) \\
Light levels & West & $\mathrm{I}$ & - & Roder et al. (2010) \\
Inorganic nutrients $\left(\mathrm{PO}_{4}{ }^{3-}, \mathrm{NO}_{\mathrm{x}}, \mathrm{NH}_{4}{ }^{+}\right)$ & East & $\mathrm{H}$ & - & \\
& West & $\mathrm{H}$ & - & - \\
\hline
\end{tabular}

$H$ high, $I$ intermediate, $L$ low. Dash indicates no measured data

\section{Materials and methods}

\section{Coral sampling}

Fragments of $P$. lutea were chiselled and branches of $P$. meandrina were pinched off their mother colonies. Leadtime was too short to initiate sampling before the height of the 2010 heat anomaly. First samples for this study were obtained on 23 May 2010, followed by repeat samplings 2 and 6 months after the heat anomaly (31 July 2010, 5 December 2010). An additional sampling was carried out after 10 months (15 March 2011) with $P$. lutea only, as $P$. meandrina numbers were dwindling, prohibiting further sampling. Reference samples prior to the May 2010 thermal anomaly were available from March 2008, corresponding to a calm NE monsoon period with similar temperature fluctuations and ranges to March 2010 despite a consistent offset of $0.7^{\circ} \mathrm{C}$ lower values (Electronic Supplementary Material, ESM Fig. S1; Mann-Whitney rank sum tests). Although possible seasonal and inter-annual differences in physiological acclimations cannot be ruled out (Fitt et al. 2000; Roder et al. 2011), the reference samples served as a reasonable estimate of the environmental and biological conditions before the 2010 heat event.

Coral fragments were collected in 15-18 m water depth at a total of six Similan Islands sites using SCUBA (Fig. 1). Sites were grouped according to exposure, yielding three western (W) and eastern (E) sites. At each site, six to ten coral colonies of each species were sampled on every occasion taking one fragment per colony from the central upper side of the colony. Coral colonies were chosen randomly taking care that fragments reflected the natural composition of the differential tissue conditions (pigmentation) at each site and that all colonies were subjected to the same light micro-environment and not shaded by other colonies. Each colony was sampled only once during the study.

\section{Photo transects}

Standardized photographs were taken $(50 \times 50 \mathrm{~cm}$ frame $)$ at all study sites in $16 \mathrm{~m}$ depth with a minimum of 29 frames per site during the heating event (May 2010) and 27 frames 6 months after the heating had ended (December 2010). The frames were placed randomly over a distance of at least $25 \mathrm{~m}$ and a maximum of $50 \mathrm{~m}$. Photographs were taken from above perpendicular to the frame with a Canon PowerShot G12 in an underwater housing. A uniform grid of $15 \times 15$ points was superimposed on each photograph and the coral point count method (CPCe; Kohler and Gill 2006) used to determine the percentage of total live and dead coral cover, as well as the cover of the genera Porites and Pocillopora and their tissue status. The status of coral tissue was assessed ranging from "fully pigmented" (with usual pigmentation), through "pale" (reduced pigmentation) and "bleached" (complete white tissue), "recently dead" (corals that just started to be overgrown by algae, but with the underlying white tissue still visible) to "dead" coral (carbonate structure that is still recognizable as a former coral colony).

\section{Temperature}

Water temperature was recorded (TidbiT v2 loggers, Onset computers; resolution $0.2^{\circ} \mathrm{C}$ ) at 3 -min intervals on the 


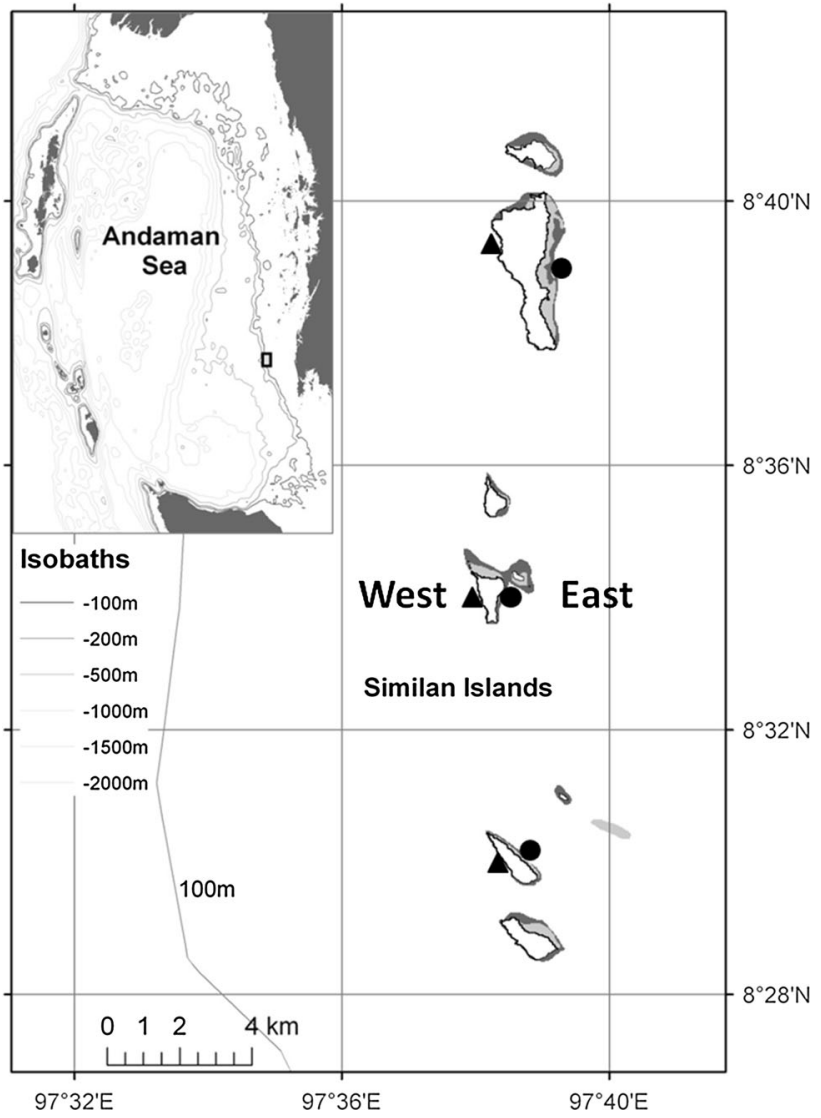

Fig. 1 Sampling locations along west (triangles) and east (circles) sides of Similan Island chain, Andaman Sea, Thailand. Symbols show locations of coral sampling. Temperature loggers and sediment traps were sited at central Similan Island. Figure modified after Jackson (2004)

west and east of the central Similan Island (Fig. 1). Temperatures recorded at this central Similan Island have previously been shown to be representative of all the Similan Islands (Schmidt et al. 2012). The temperature loggers were deployed in $15 \mathrm{~m}$ water depth from November 2007 to April 2008 and from November 2009 through March 2011 after intercalibration with a high precision digital thermometer (Amarell ama-digit ad 3000 th). Because the arithmetic mean is sensitive to extreme values, temperature data are described with the most frequent (or mode) values in the record calculated as daily running modes (Fig. 2). As a measure of the intensity and extent of heat stress and cooling intensity, temperature anomalies were calculated as cumulative degree heating weeks (DHW; cf. Wall et al. 2014) as this is the most commonly used heat stress index for bleaching events. The higher resolution in days of heating and cooling (DD in ${ }^{\circ} \mathrm{C} \mathrm{d}$; Schmidt et al. 2012) was used for a more precise description of the actual temperature conditions especially due to the short-term cold water intrusions. Temperature values above the NOAA bleaching threshold of $30.62{ }^{\circ} \mathrm{C}$ (Wall et al. 2014) were considered as heating (DHW and degree days heating, DDH). Temperature values below the daily running mode before and after the daily mode exceeded the bleaching threshold were considered as cooling (degree days cooling: DDC). The obtained temperature anomalies were multiplied by the sampling interval ( $3 \mathrm{~min}$, corresponding to $0.0021 \mathrm{~d}$ ). The cooling and heating intensity values were obtained by summing all negative and positive temperature anomalies, respectively, for each time period between the single sampling occasions.

\section{Sedimentation rates}

Sedimentation rates were assessed to determine relative changes between seasons and sides, particularly with regard to the effect of the SW monsoon and its differential impact on the east and west of the island. For this purpose, three sediment traps were deployed on each side (W and E) of the central Similan Island (Fig. 1). Detailed descriptions of the traps are given in Wall et al. (2012). The traps were deployed in November 2009 and exchanged during each sampling occasion until the end of March 2011 (total samplings: 5). Macro-invertebrates were removed from the sediment samples and the samples dried at $80{ }^{\circ} \mathrm{C}$ for $24 \mathrm{~h}$ until the dry weight was constant. Sedimentation rates were calculated in mg dry mass $\mathrm{cm}^{-2} \mathrm{~d}^{-1}$.

\section{Fluorescence measurements}

Photophysiological responses of Symbiodinium were assessed by chlorophyll fluorescence analyses using a pulse amplitude-modulated fluorometer (Diving-PAM). Immediately after collection, coral fragments were placed in a seawater tank and dark-adapted for $30 \mathrm{~min}$ prior to each measurement, which is enough time for all photoprotective mechanisms in the corals to relax (Saxby et al. 2003). The fibre optic probe of the PAM was placed at a fixed distance of $1 \mathrm{~cm}$ to the coral surface. Activity of photosystem II (PSII) and non-photochemical quenching (NPQ) kinetics of $P$. lutea and $P$. meandrina were explored in two different ways, each repeated 3-5 times per fragment on different locations on the fragment surface. Firstly, maximum potential quantum yield (MQY) $\left[F_{\mathrm{v}} / F_{\mathrm{m}}=\left(F_{\mathrm{m}}-F_{0}\right) / F_{\mathrm{m}}\right]$, a proxy for the photosynthetic efficiency of PSII, was recorded. Each fragment was pulsed with a weak $\left(<1 \mu \mathrm{mol} \mathrm{m}{ }^{-2} \mathrm{~s}^{-1}\right)$ red light to obtain $F_{0}$ followed by a 1-s pulse of saturating actinic light $\left(>5000 \mu \mathrm{mol} \mathrm{m}^{-2} \mathrm{~s}^{-1}\right)$ to determine $F_{\mathrm{m}} \cdot F_{\mathrm{v}} / F_{\mathrm{m}}$ was calculated in the conventional manner as $F_{\mathrm{m}}-F_{0} / F_{\mathrm{m}}=F_{\mathrm{v}} / F_{\mathrm{m}}$ (Schreiber 2004). Secondly, each fragment was exposed to actinic light for $1 \mathrm{~min}$ $\left(600 \mu \mathrm{mol} \mathrm{m}{ }^{-2} \mathrm{~s}^{-1}\right)$, after which the fluorescence had reached a steady state (Hoegh-Guldberg and Jones 1999). Minimum and maximum fluorescence $\left(F^{\prime}\right.$ and $F_{\mathrm{m}}{ }^{\prime}$ of light- 


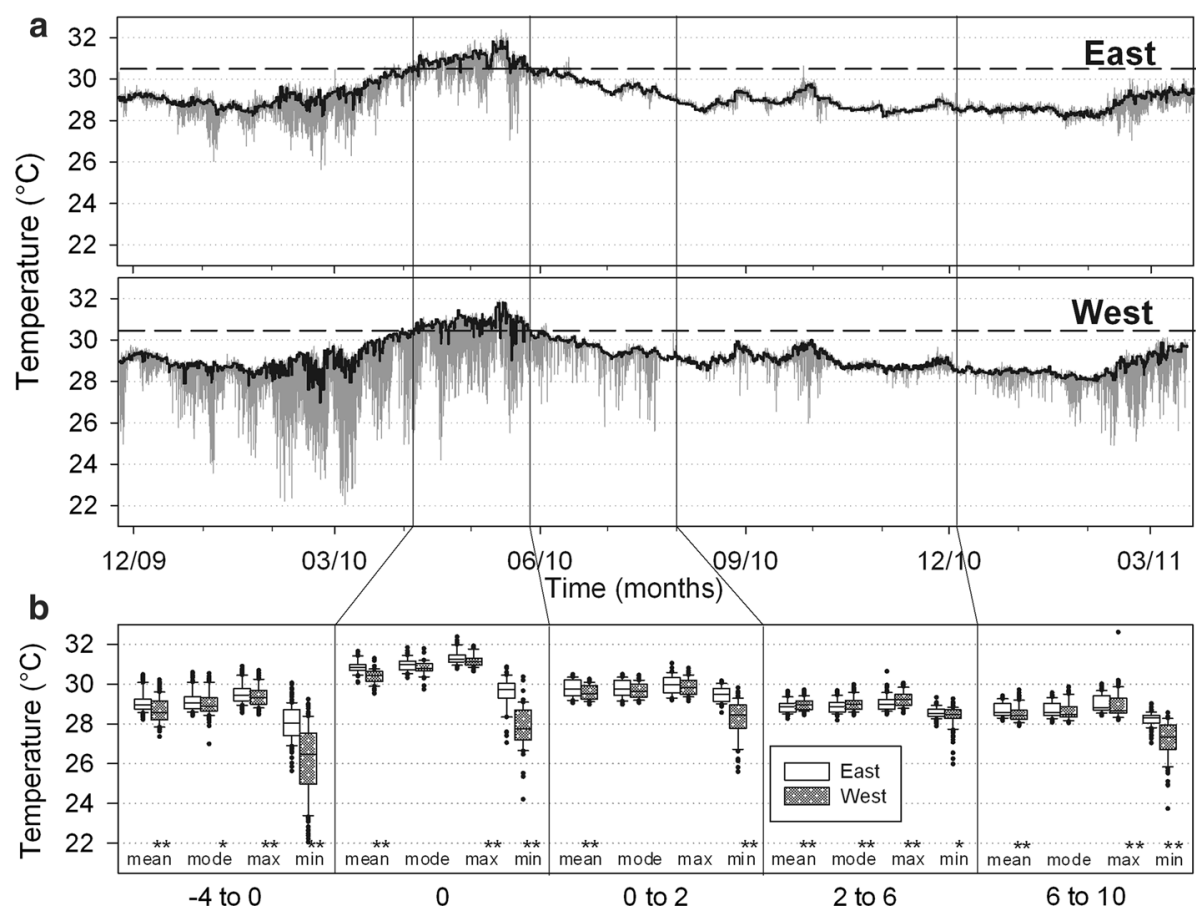

Fig. 2 a Temperature record at sheltered east side of central Similan Island and west side exposed to large-amplitude internal waves (LAIW) and monsoon in $16 \mathrm{~m}$ depth from 24 November 2009 to 31 March 2011: raw data (grey) logged at 3-min intervals and daily running temperature mode (black) with bleaching threshold (dashed line) of $30.62{ }^{\circ} \mathrm{C}$. b Central tendency box plots (median as solid line with 25 th and 75 th percentile and non-outlier range, mean as dashed line) with extremes (dots) of daily mean, mode, maxima and minima temperature values at west and east sites for five periods before and after heat stress period ( -4 to 0: 24 November 2009 to 5 April 2010; 0: 6 April to 26 May; 0 to 2: 27 May to 31 July, 2 to 6: 1 August to 6 December; 6 to 10: 7 December 2010 to 15 March 2011). Asterisks indicate significant differences between west and east sites (nonparametric Mann-Whitney rank sum test; ${ }^{*} p<0.05$; ${ }^{*} p<0.01$ )

separate symbionts from coral host tissue (Grottoli et al. 2004). Total protein content of the coral host tissue was measured using the DC protein assay (Bio-Rad), a standard curve established using bovine serum albumin, and absorbance read spectrophotometrically (Shimadzu, UV-1800 spectrophotometer) at $750 \mathrm{~nm}$ (Lowry et al. 1951).

\section{Data analyses}

The software Statistica v 9 and the freeware program R ( R Core Team 2014) were used for statistical analyses. Data did not meet assumptions of normal distribution and homogeneity of variances with Kolmogorov-Smirnov and Levene's tests even after transformation. Hence, the effect of sampling time and exposure (W or E) on coral and Symbiodinium traits, and sedimentation rates was analysed using a nonparametric Kruskal-Wallis and median test followed by pairwise rank comparisons (Mann-Whitney U test). The effect of exposure (W vs. E) on temperature conditions (daily mean, mode, maxima and minima) was tested with a nonparametric, two-tailed Mann-Whitney U test.

Non-metric multidimensional scaling (nMDS) ordination gives an overall visualization of the development in coral and Symbiodinium traits for both coral species. The 
traits were first standardized to have a mean of zero and standard deviation of one (i.e., dimensionless) by first subtracting the mean (centring) and then dividing by the standard deviation (scaling). Sample similarity was calculated using Euclidean distance. Vectors showing the direction of highest correlation between each of the coral and Symbiodinium traits and the nMDS coordinates were calculated using the "envfit" function of the R package "vegan", version 2.2-0 (Oksanen et al. 2013).

The effects of environmental changes on the individual coral and Symbiodinium traits were explored by calculating the temporal changes $(\delta)$ in traits between sampling dates. The $\delta$ values were calculated separately for each sampling site and the March 2008 reference. The reference data were used as a representative March sample and aligned with the environmental conditions measured in 2010. Redundancy analysis (RDA) was used to test the predictive power of environmental variability on all changes in coral and Symbiodinium traits within a single multivariate model. Coral and Symbiodinium $\delta$ traits were standardized through scaling (divided by their SD) but not centred. Cumulative environmental variables [positive temperature anomaly (DDH) and sedimentation] were standardized by centring and scaling prior to analysis. Significance of environmental terms in the RDA was determined with an ANOVA-like permutation test, PERMANOVA, which results in a pseudo-F value. The multivariate analyses were conducted with the R package "vegan", version 2.2-0 (Oksanen et al. 2013).

\section{Results}

\section{Temperature}

The strong heat event in spring 2010 resulted in considerable increases of daily mean temperatures and maxima above the bleaching threshold of the region $\left(30.62{ }^{\circ} \mathrm{C}\right)$ independent of exposure and orientation of study reef sites along the Similan Islands (Table 2; Fig. 2). Temperature modes were similar at $\mathrm{W}$ and $\mathrm{E}$ locations. However, temperature variability resulted in differences in arithmetic means, which were lower at $\mathrm{W}$ sites. The bleaching threshold was exceeded for $44 \mathrm{~d}$ at $\mathrm{E}$ sites, but only for 16 $\mathrm{d}$ at $\mathrm{W}$ sites (Fig. 2; Table 2) with corresponding twofold differences in cumulative heat stress (DDH) between 6 April and 26 May. LAIW were evident especially at W sites and prevailed until the end of the heat event providing almost threefold more cooling (DDC) to $\mathrm{W}$ corals compared to E corals. Although the magnitude of LAIW decreased after May, average and minimum daily temperatures remained lower during the subsequent months of recovery (Fig. 2b).

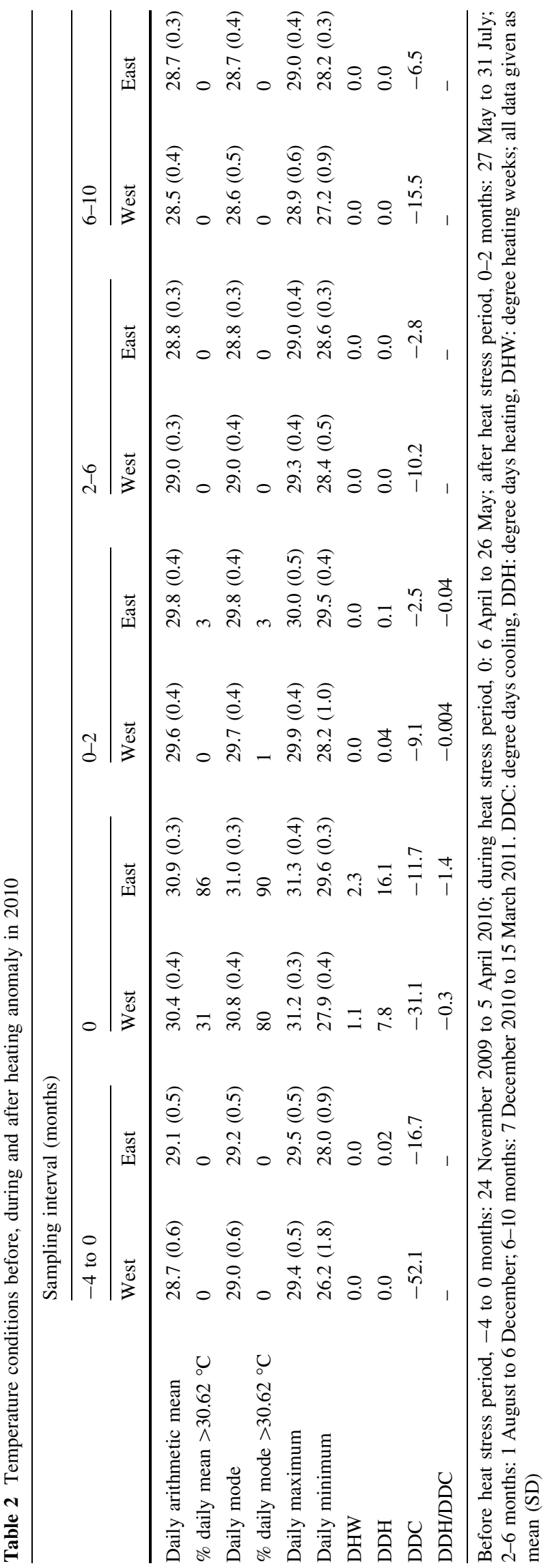




\section{Sedimentation}

Sedimentation rates (ESM Fig. S2) showed strong seasonality with almost identically low values at $\mathrm{W}$ and $\mathrm{E}$ sites during the calm NE monsoon $\left(2.67 \pm 1.0 \mathrm{mg} \mathrm{cm}^{-2} \mathrm{~d}^{-1}\right.$ at $\mathrm{W}$ versus $1.76 \pm 1.15 \mathrm{mg} \mathrm{cm} \mathrm{d}^{-2} \mathrm{~d}^{-1}$ at $\mathrm{E}$ sites: KruskalWallis ANOVA: $\chi^{2}=5.667$, $\left.\mathrm{df}=24, p=0.129\right)$. They increased at $\mathrm{W}$ sites during the $\mathrm{SW}$ monsoon from May until end of October $\left(101.83 \pm 34.2 \mathrm{mg} \mathrm{cm}^{-2} \mathrm{~d}^{-1}\right.$ at $\mathrm{W}$ versus $1.11 \pm 0.24 \mathrm{mg} \mathrm{cm}^{-2} \mathrm{~d}^{-1}$ at $\mathrm{E}$ sites: KruskalWallis ANOVA: $\chi^{2}=28.491$, $\mathrm{df}=35, p<0.001$ ).

\section{Coral cover and tissue status}

The fraction of live cover of Porites spp. relative to total living coral cover was similar at $\mathrm{E}$ and $\mathrm{W}$ sites and did not change between May (heat event) and December 2010 (6 months after heat anomaly had ended; Fig. 3a; KruskalWallis ANOVA: $\chi^{2}=5.05$, df $=3, p=0.17$ ). Differences in colony condition between $\mathrm{E}$ and $\mathrm{W}$ in May or December 2010 were not statistically significant (despite apparently different means in May with $68.9 \%$ bleached and $21.8 \%$ recently dead individuals at $\mathrm{E}$ versus 34.1 and $0.9 \%$ at $\mathrm{W}$ sites, respectively; Fig. 3d, e), and $9.2 \%$ pale and $0.2 \%$ healthy individuals at $\mathrm{E}$ versus 58.3 and $6.8 \%$ at $\mathrm{W}$, respectively, Fig. 3b, c). In December 2010 fractions of pale and fully re-pigmented (healthy) colonies were similar at $\mathrm{E}$ and $\mathrm{W}$ sites (Fig. 3b, c) with clearly more healthy individuals than in May 2010 (Kruskal-Wallis ANOVA: $\chi^{2}=9.39$, df $=3, p=0.02$ ). In May 2010, $>95 \%$ of Pocillopora spp. were bleached. There were insignificant W-E differences in per cent cover in May and a complete loss of living individuals at E sites by December 2010 (Fig. 3a; Kruskal-Wallis ANOVA May versus December 2010: $\chi^{2}=8.97$, df $=3, p=0.03$ ). At $\mathrm{W}$ sites, only $9.8 \%$ of Pocillopora spp. had died, while $33.3 \%$ recovered to pale and $56.9 \%$ to fully pigmented colonies (Fig. 3b-e).

\section{Coral and Symbiodinium traits}

Before the heat event (samples collected in March 2008), both coral species exhibited similar physiological traits such as host protein content, symbiont densities, chlorophyll-a concentrations, and photophysiological response (MQY and EQY) at $\mathrm{W}$ and $\mathrm{E}$ sites. During and after the heat event, however, the responses of the corals diverged (Fig. 4; ESM Table S1): P. meandrina traits decreased strongly at all sites during the heat event. No recovery was visible except for chlorophyll-a concentration and zooxanthellae densities at $\mathrm{W}$ sites, which acquired pre-heat values 2 and 6 months after the heat event had ended, respectively. Porites lutea traits also declined at E sites during the heat event followed by a detectable recovery

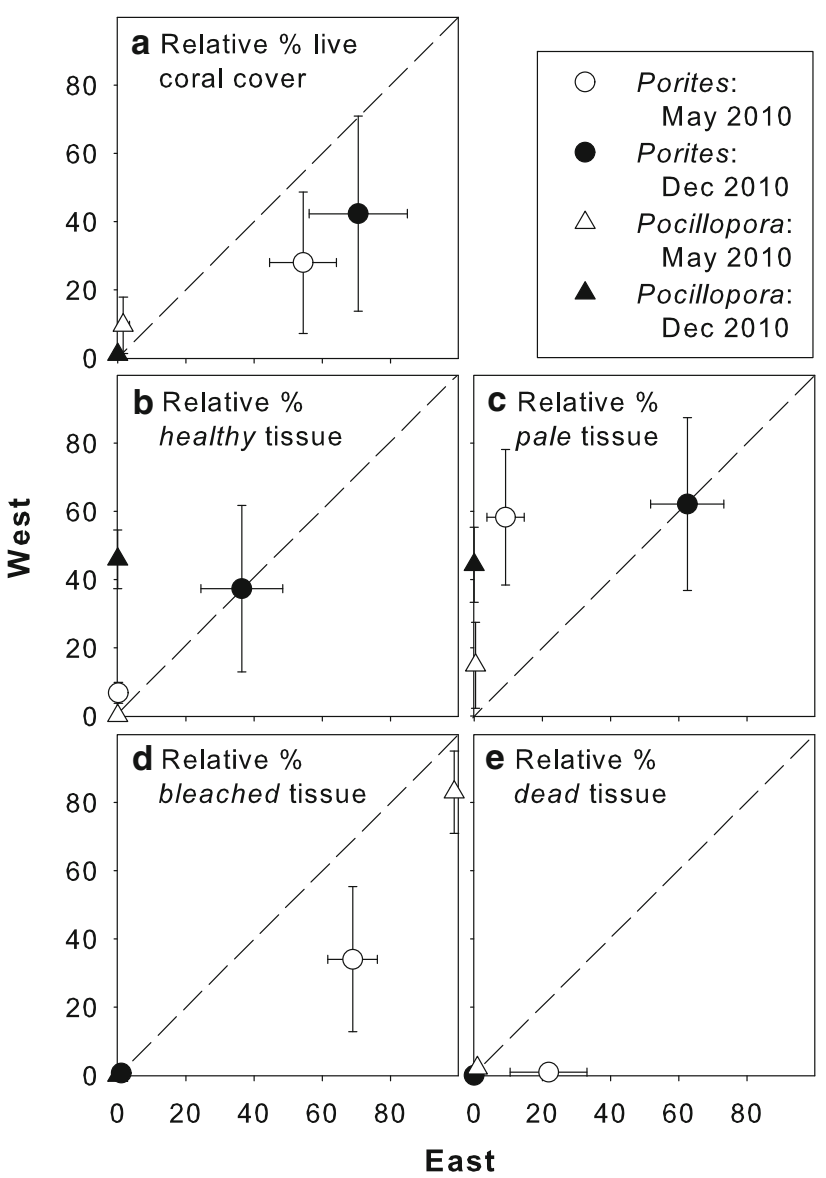

Fig. 3 Relative per cent live coral cover and tissue condition of the genera Porites and Pocillopora during a heating event (May 2010) and 6 months after heating had ended (December 2010) in western (exposed) and eastern (sheltered) Similan Islands. Coral genus (Porites and Pocillopora) cover as a fraction of total live coral cover (a), and coral tissue condition displayed as the amount of "healthy" (fully pigmented) (b), "pale" (c), "bleached" (d) or "dead" (died recently) (e) tissue as a fraction of the total tissue of each genus

starting in most cases 6 months after the heat event had ended and resulting in values similar to initial pre-heating conditions after 10 months recovery. At $\mathrm{W}$ sites, $P$. lutea reacted less intensely to the heat with no statistically detectable decreases in zooxanthellae densities and mitotic index. Chlorophyll-a concentrations, MQY, EQY and coral protein content showed a decline with the heat anomaly compared to the 2008 samples but not as strong as at E sites. Except for the photophysiological parameters (MQY, EQY), all others recovered comparatively quickly with clearly increased values 2 months after the heat event. After 6 months recovery, in December 2010, the photophysiological response (MQY, EQY) showed values similar to those measured before the heat event in March 2008. The parameters measured in the tissue samples collected in December 2010 deviated from this trend: most Symbiodinium traits (densities, mitotic index and pigment 
a Porites lutea

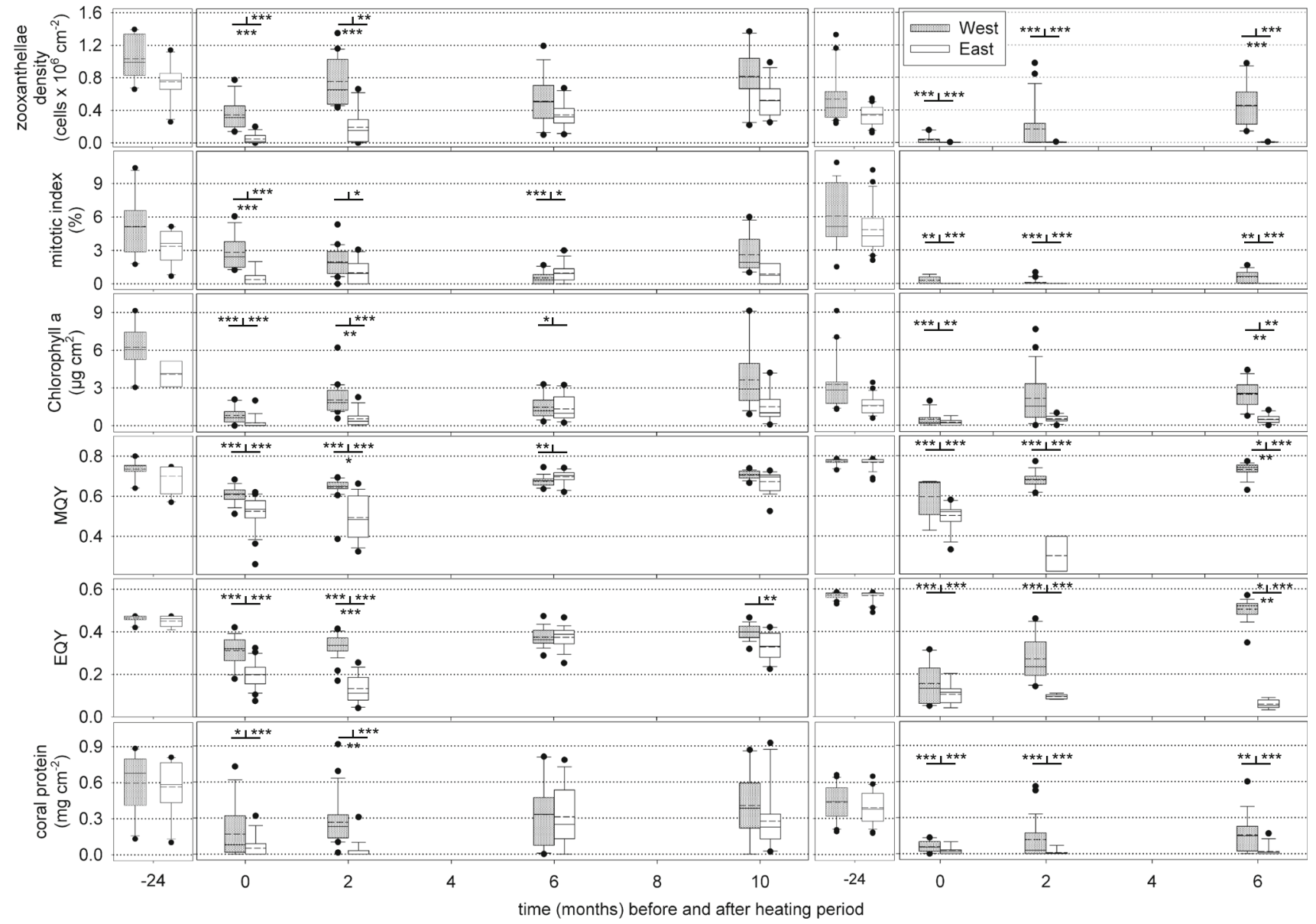

Fig. 4 Coral symbiont and host traits of a Porites lutea and b Pocillopora meandrina at west (dark) and east (white) sides of Similan Islands over time. Central tendency box plots (median as solid line with 25 th and 75 th percentile and non-outlier range, mean as dashed line) with extremes (dots) of symbiont status (density and chlorophyll-a content) and photosynthetic efficiency given as maximum quantum yield (MQY: $F_{\mathrm{v}} / F_{\mathrm{m}}$ ) and effective quantum yield (EQY: $\Delta \mathrm{F} / F_{\mathrm{m}}{ }^{\prime}$ ), and of coral protein content at consecutive sampling occasions before ( -24 months) and during heating ( 0 months) as well

concentrations) of W samples showed a stagnation or slight decline in their recovery resulting in lower values than at $\mathrm{E}$ sites. However, after 10 months all coral and Symbiodinium traits at $\mathrm{W}$ sites had recovered to pre-heat values. The 2-D nMDS plots (Fig. 5) provide accurate representations of the differences between coral and Symbiodinium traits sampled over time, as indicated by low associated stress values $(\leq 0.05)$ (Clarke and Warwick 2001). All trait vectors were highly correlated with nMDS coordinates (all $p<0.001$ ) and show that lower trait values, as measured following the heat event, were strongly associated with positive nMDS first axis values, while recovery trajectories returned towards negative values on the left side of the plot. as 2, 6 and 10 months after heating had ended. Asterisks indicate results of nonparametric Kruskal-Wallis ANOVA and median test followed by multiple comparisons of mean ranks with side (west and east) and sampling date as treatment factors; asterisks below lines: west versus east comparison at each point in time, above lines: comparison with reference conditions 24 months before heating had started (W comparisons left asterisks, E comparisons right asterisks). Significance levels: $* p<0.05$; $* * p<0.01 ; * * *<0.001$. See ESM Table S1 for detailed results

\section{Relation between coral and Symbiodinium traits and environmental parameters}

There was an overall effect of heat (DDH) in the reduction of all coral and Symbiodinium traits. The RDA shows most of the variance related to the first axis (RDA1, Fig. 6; Table 3), which explains 63 and $65 \%$ of the variance in the coral and Symbiodinium traits of $P$. lutea and P. meandrina, respectively. The vector showing the DDH scores is mainly oriented towards the direction of negative RDA1 values, which is also the direction of negative $\delta$ coral and Symbiodinium traits (grey text in Fig. 6). The PERMANOVA test indicated that DDH was a significant predictor for $\delta$ coral and Symbiodinium traits $(p<0.001$ for both coral species). 
Fig. 5 Non-metric multidimensional scaling (nMDS) of $\mathbf{a}, \mathbf{b}$ Porites lutea and $\mathbf{c}, \mathbf{d}$ Pocillopora meandrina coral and Symbiodinium traits. a, $\mathbf{c}$ nMDS scores of traits by sample (red $=$ West,

blue $=$ East $)$ and directions of highest correlation between specific traits and samples (grey vectors). Numbers indicate number of months since heating event, "R" refers to reference sample taken prior to heating event (March 2008). Grey text indicates specific coral and Symbiodinium traits

( $C$ chlorophyll-a, $E$ effective quantum yield, $M$ mitotic index, $P$ protein, $Y$ maximum quantum yield, $Z$ zooxanthellae). b,

d Dominant temporal trajectory of traits patterns by island side $($ red $=$ West, blue $=$ East $)$

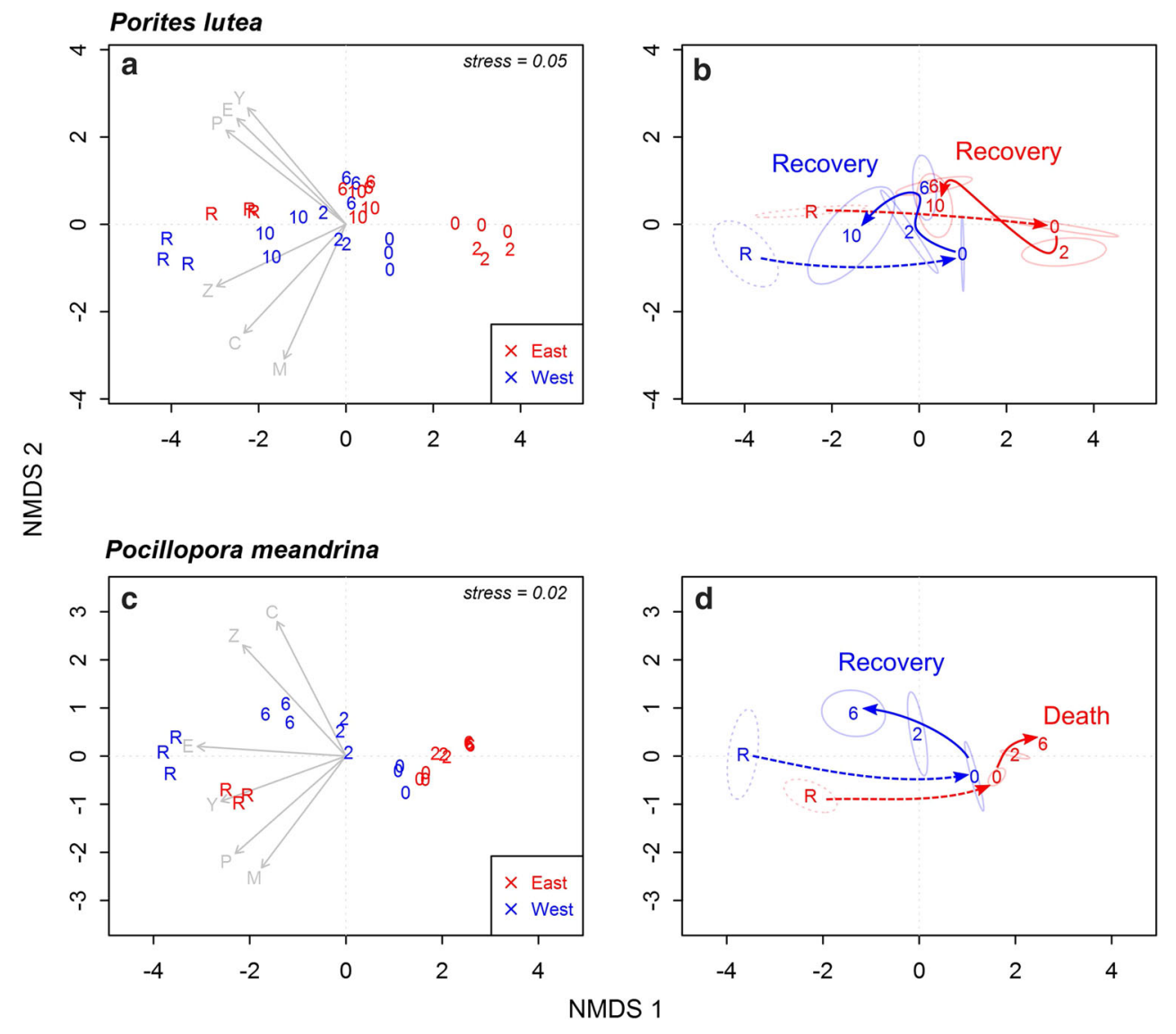

a Porites lutea

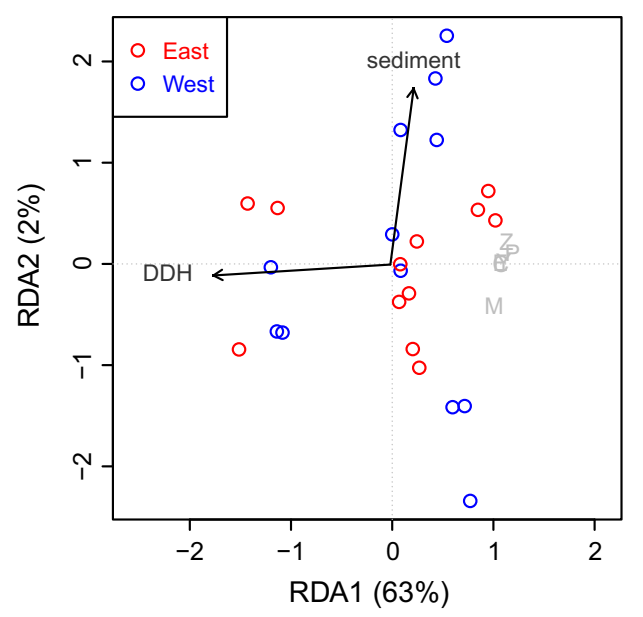

Fig. 6 Redundancy analysis (RDA) scores for temporal changes $(\delta)$ in coral and Symbiodinium traits at west (blue) and east (red) sites as predicted by indices of cumulative environmental variability (degree days heating, DDH, and sedimentation) for a Porites lutea and b Pocillopora meandrina. All indices have been centred and scaled to

Sedimentation was only significant as a predictor for $\delta$ coral and Symbiodinium traits of $P$. meandrina, although to a much lower degree than DDH $(p=0.049)$. For both

\section{b Pocillopora meandrina}

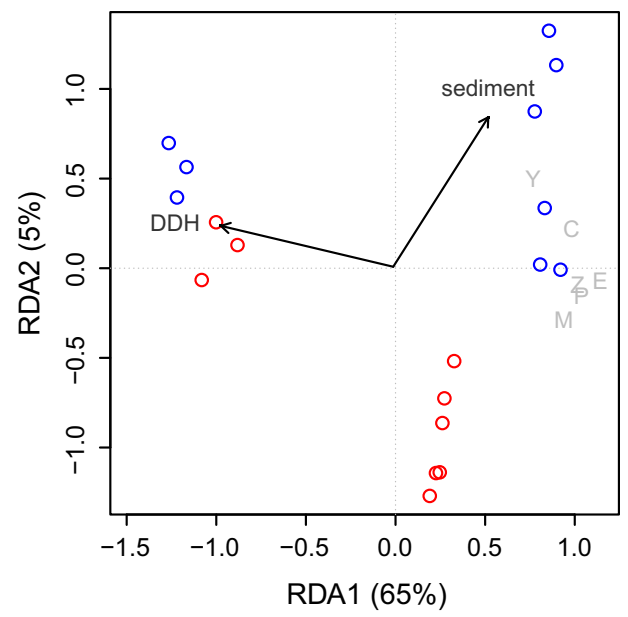

account for differing units. Sample scores (circles) are plotted along with the eigenvalue-scaled coral traits (grey text: $C$ chlorophyll-a, $E$ effective quantum yield, $M$ mitotic index, $P$ protein, $Y$ maximum quantum yield, $\mathrm{Z}=$ zooxanthellae)

species, sedimentation was associated with the second RDA axis. In case of $P$. meandrina, this axis was associated with a separation between $\mathrm{W}$ and $\mathrm{E}$ sites (Table 3; Fig. 6). 
Table 3 PERMANOVA test results of redundancy analysis of cumulative environmental indices (sedimentation, degree days heating: $\mathrm{DDH}$ ) as predictor variables on coral condition changes $(\delta)$ as response variables for Porites lutea and Pocillopora meandrina

\begin{tabular}{llrlrr}
\hline & Term & df & Variation (\%) & pseudo-F & $p$ \\
\hline Porites lutea & DDH & 1 & $3.54(63 \%)$ & 37.37 & $<0.001$ \\
& Sedimentation & 1 & $0.13(2 \%)$ & 1.38 & 0.25 \\
& Residual & 21 & $1.99(35 \%)$ & & \\
Pocillopora meandrina & DDH & 1 & $2.28(55 \%)$ & 22.97 & $<0.001$ \\
& Sedimentation & 1 & $0.38(9 \%)$ & 3.79 & 0.049 \\
& Residual & 15 & $1.49(36 \%)$ & & \\
\hline
\end{tabular}

\section{Discussion}

The differential response of corals at $\mathrm{W}$ and $\mathrm{E}$ sites to elevated temperatures with and without LAIW, respectively, shows that LAIW exposure mitigated bleaching in the two coral species $P$. lutea and $P$. meandrina during the extreme heat event in the Andaman Sea 2010. Our study supports earlier suggestions that internal waves may alleviate the deleterious effects of prolonged periods of anomalously high sea surface temperatures (Sheppard 2009; Phongsuwan and Chansang 2012; Storlazzi et al. 2013). It gives an explanation at an eco-physiological and organismic level for the spatial differences in coral community bleaching responses to LAIW (Wall et al. 2014).

The temperature time series reveal that, during the period of extraordinary warm surface water temperatures in the Similan Islands, LAIW caused intermittent cooling in reef areas at a depth of $15 \mathrm{~m}$ (Table 2; Fig. 2). During the heat period, daily temperature minimum values in the west were consistently $2{ }^{\circ} \mathrm{C}$ below the values in the east. The absence of LAIW at $\mathrm{E}$ sites resulted in strong differences in heating and cooling between the island sides and, subsequently, affected the capacity to alleviate heat stress. In fact, the temperature time series shows more than $50 \%$ greater heat stress at $\mathrm{E}$. This is consistent with the significantly lower bleaching of both coral species at W sites compared to E sites (Figs. 3, 4, 5; Wall et al. 2014). The heat event coincided with a strong LAIW effect, resulting in a substantial mitigation of heat intensity (cf. DHW and $\mathrm{DDH}, \mathrm{W}$ vs. E; Table 2). In contrast to wind-driven upwelling (Riegl and Piller 2003), LAIW caused shortterm but intermittent periods of cooling rather than extended periods of cooling and hence, relief from heat (cf. similar mode temperatures but different arithmetic means between $\mathrm{W}$ and $\mathrm{E}$; Table 2). The difference in heat stress is reflected in higher proportions of fully pigmented and pale colonies at the LAIW-exposed $\mathrm{W}$ sites and much higher proportions of bleached and recently dead corals at the sheltered E sites (Figs. 3, 4).

Another positive effect of LAIW temperature variability might be that $\mathrm{W}$ corals may exhibit acclimation or adaptation for tolerance to disturbance, which are potentially beneficial during heat stress conditions (Oliver and
Palumbi 2011; Ash 2014). Coral temperature thresholds can be strongly influenced by phenotypically altered tissue parameters (Bellantuono et al. 2012) and/or thermal history (Middlebrook et al. 2008). Hence, corals exposed to temperature variations have been shown to have a higher temperature resistance (Barshis et al. 2013). Most studies, however, concentrate on the influence of increased temperatures (e.g., Brown et al. 2000; Oliver and Palumbi 2011; Barshis et al. 2013). Yet studies on corals influenced by cold water fluctuations have indicated that these corals exhibit enhanced heat resistance due to supposed acclimations to recurring stress (Putnam et al. 2010; Mayfield et al. 2013). This study concords with this hypothesis, since LAIW-exposed corals used to large short-term variations in temperature were less affected by variations from longterm average temperatures than sheltered corals (see also McClanahan et al. 2007a; Oliver and Palumbi 2011).

LAIW exposure not only implies a cooling effect but also enhanced water motion and current velocities (Roder et al. 2010). The arrival of LAIW in the reef areas induces a temporary exchange of water masses surrounding the corals until the return flow of the deep water masses clears and allows for warm surface waters to return. This periodic exchange may be important in removing deleterious substances such as oxygen radicals from the direct vicinity of the corals (Nakamura and van Woesik 2001), decreasing oxidative stress, increasing photosynthetic efficiency (Finelli et al. 2006) and, thus, further mitigating the effects of heat and increasing the survival of corals (Nakamura and van Woesik 2001). Originating in deep waters, LAIW supply inorganic nutrients (Schmidt et al. 2012) and plankton (Roder et al. 2010) to the corals providing them with better physiological constitution, higher energetic status and finally better survival rates under temperature stress (Ezzat et al. 2015).

Although the monsoon and LAIW both impact from the same westerly direction, they are temporally decoupled. Surface wave action, sediment resuspension and accumulation play a major role during the stormy SW monsoon but only on the western side of the Similans (Wall et al. 2012; Table 1). Despite the use of artificial sediment traps at only one $\mathrm{E}$ and one $\mathrm{W}$ location, the sedimentation values are roughly comparable and representative for the whole 
archipelago (Schmidt et al. 2012). Although different currents between sides and seasons may have introduced some unknown bias, sedimentation rates diverged strongly between $\mathrm{E}$ and $\mathrm{W}$ sites at the height of the wet season (July; ESM Fig. S2). Nevertheless, changes in the physiological constitution of the corals were comparatively small (Fig. 4; Table 3). The effect of the SW monsoon, and subsequent increases in sedimentation, is indicated in the mitotic index and the photosynthetic efficiency of both coral species (Fig. 4) and in the generally retarded recovery of $P$. lutea after the heat anomaly (Fig. 5, month 6). However, a reduction or delay in the recovery of coral protein reserves was not observed (Fig. 4). This might have been expected because the removal of sediment is energetically costly and results in lack of regeneration and repair (Riegl and Branch 1995). It is more likely that reduced light levels at $\mathrm{W}$ sites, which have been shown to occur during the calm NE monsoon as well (Schmidt et al. 2012), may have contributed to reduced physiological stress both during and after the heat period. In contrast the comparatively higher light intensities at E sites (Schmidt et al. 2012) may have resulted in an additional stress for the corals and their symbionts (Lesser 2006).

The lack of samples immediately before the May 2010 thermal anomaly was compensated by using available samples from March 2008. The fact that both coral species at $\mathrm{W}$ sites largely recovered back to similar traits as in the reference samples (Figs. 4, 5), suggests that this is a stable level at these sites during the early year.

Differences in bleaching response and subsequent recovery between the two coral species studied can be largely attributed to their species-specific susceptibility or tolerance. In the Similan Islands, Porites has been shown to associate with the same zooxanthellae type (C15) independent of exposure (LaJeunesse et al. 2010; Buerger et al. 2015) which indicates no contribution of Symbiodinium to differences in thermal tolerance of Porites. Pocillopora, however, was found to associate with several zooxanthellae types within clades C and D (LaJeunesse et al. 2010). This variability in the coral-symbiont association could imply possible adaptations to differences in environmental conditions or thermal stress. The lack of information on the specific genotypes associated with the corals sampled for the present study allows only for speculations on their possible contributions to the differential bleaching responses of Pocillopora at E and W sites. Nevertheless, laboratory studies on $P$. lutea from the Similans indicated a high level of phenotypic plasticity and memory regarding environmental conditions at their origin (Buerger et al. 2015). This phenotypic plasticity may be influenced by Symbiodinium even though the symbionts are genetically identical in $P$. lutea. The thermal threshold of the holobiont is nevertheless strongly influenced by the coral host (Baird et al. 2008). Bleaching susceptibility has been related to colony morphology with massive species often less susceptible than branching forms (Loya et al. 2001, McCowan et al. 2012). Porites lutea, in contrast to P. meandrina, is known as especially robust and tolerant to environmental stress, especially warming (McClanahan et al. 2007b) and acidification (Fabricius et al. 2011). Similarly, our findings show massive $P$. lutea responding less intensely to heat stress and recovering faster and more efficiently than branching $P$. meandrina (Figs. 4,5 ). In contrast to $P$. lutea, $P$. meandrina prefers habitats with high water movement (Jokiel 1978). This may explain its generally higher abundance at $\mathrm{W}$ sites compared to $\mathrm{E}$ sites and may have contributed to the reduced heat effect in the $\mathrm{W}$ both by better initial conditions and eased conditions during and after the heat event. Differences in susceptibility have also been attributed to energy reserves and the capacity of corals to store proteins and lipids. Bleached corals deprived of endosymbionts and the associated photosynthetic energy supply have a higher chance of recovery when more energy reserves are available (Grottoli et al. 2004) or when they are able to compensate by energy uptake through heterotrophic feeding (Grottoli et al. 2006). Tissue layer thickness is an indicator of biomass and stored energy, and branching corals generally exhibit a thinner tissue layer than massive corals (Loya et al. 2001). We found branching $P$. meandrina contained approximately half the amount of protein per surface area than $P$. lutea during pre-heat and post-recovery phases (Fig. 4), which corresponds to their reduced capacity to deal with heat stress. Both coral species may have benefited from enhanced nutrient input by LAIW into W reef areas (Schmidt et al. 2012), which has been shown to foster protein reserves (Roder et al. 2011). This adds to the effect of environmental drivers and the possibility that heat shock proteins could have been produced at $\mathrm{W}$ sites due to LAIW-induced thermal fluctuations (Lesser 2006). Heat shock proteins are known to increase thermal resistance in corals (Fitt et al. 2009).

Both corals showed a decline in all Symbiodinium traits and coral protein content in response to heat (Figs. 4, 5), but the decline was less in P. lutea. Even during the height of the heat period $P$. lutea held symbionts, pigmentation and protein reserves and was able to recover after the stress period. At W sites, exposure to LAIW led to $50 \%$ fewer bleached $P$. lutea, ensured a faster and more efficient recovery (Figs. 3, 4) and reduced mortality (Wall et al. 2014) compared to E sites. The effect of LAIW on bleaching resistance and survival was even more pronounced in $P$. meandrina, where $\mathrm{W}$ colonies were able to maintain symbiont and energy reserves at the height of the heat event, while E colonies showed a complete depletion of symbiont and energy reserves and died (Figs. 4, 5). Differences in post-bleaching development between coral species, and especially high mortality of heat- 
sensitive species, has been widely documented with fundamental changes in post-bleaching communities shifting to mainly heat tolerant species (McClanahan et al. 2007b; Wall et al. 2014) at the expense of species diversity (McClanahan et al. 2007b). The post-bleaching community at $\mathrm{W}$ sites maintained the same species composition as before the heat event (Wall et al. 2014), suggesting a re-stocking of E reef areas with locally extinct species. Hence, the likely stressful but tolerable environmental conditions due to LAIW impact, including strong water movement, temperature and water chemical fluctuations as well as reduced light conditions, seem to offer a protection from heat events, and foster the resistance of susceptible species by providing coral refuge conditions. The fact that bleaching events have been predicted to occur on an annual or biannual basis by the middle of the century (van Hooidonk et al. 2013) focuses attention even more on naturally resilient areas such as LAIW-exposed reefs where bleaching-susceptible coral species can survive leading to maintenance of biodiversity and reef integrity.

This study indicates that LAIW may provide local refugia for $P$. meandrina and possibly other bleachingsusceptible corals. The ubiquitous occurrence of LAIW in macrotidal tropical areas (Jackson 2007) evokes the hope that these areas can contribute to sustaining coral diversity in a future with more frequent bleaching events. As warming and thermal stratification are major factors involved in bleaching and LAIW, respectively, it will be crucial to understand the interplay between coral ecophysiology and coastal hydrodynamics in predicting how corals may fare in a warming planet.

Acknowledgments S. Khokiattiwong, the Director and staff of the Phuket Marine Biological Center, and the Similan Island National Park staff kindly assisted and supported logistics of the study. J. Laudien assisted with diving and L. Fillinger compiled the map figure. This study was funded by the German Federal Ministry for Education and Research (Grant number: 03F0608B, Bioacid 3.2.3, Coral calcification in marginal reefs), by the PEOPLE-2007-1-1-ITN Marie Curie Action: CalMarO (Calcification by Marine Organisms, 215157), and by the National Research Council of Thailand (NRCT). Research permission was provided by the NRCT (No. 0002/5675) and additionally from the National Park Authorities. The authors declare that no conflicts of interest exist.

Author contributions GMS, MW, CJ, and CR conceived and designed the experiment, GMS, MW, and CJ performed the fieldwork and sampling, MT and GMS analysed the output data and created figures and tables, GMS wrote the first draft of the manuscript and MT, MW and CR contributed substantially to the revisions.

Open Access This article is distributed under the terms of the Creative Commons Attribution 4.0 International License (http://crea tivecommons.org/licenses/by/4.0/), which permits unrestricted use, distribution, and reproduction in any medium, provided you give appropriate credit to the original author(s) and the source, provide a link to the Creative Commons license, and indicate if changes were made.

\section{References}

Ash C (2014) Hot and bothered corals can cope. Science 344:868

Baird AH, Bhagooli R, Ralph PJ, Takahashi S (2008) Coral bleaching: the role of the host. Trends Ecol Evol 24:16-20

Barshis DJ, Ladner JT, Oliver TA, Seneca FO, Traylor-Knowles N, Palumbi SR (2013) Genomic basis for coral resilience to climate change. Proc Nat Acad Sci U S A 110:1387-1392

Bellantuono AJ, Hoegh-Guldberg O, Rodriguez-Lanetty M (2012) Resistance to thermal stress in corals without changes in symbiont composition. Proc $\mathrm{R}$ Soc Lond B Biol Sci 279:1100-1107

Brown BE, Phongsuwan N (2012) Delayed mortality in bleached massive corals on intertidal reef flats around Phuket, Andaman Sea, Thailand. Phuket Marine Biological Center Research Bulletin 71:43-48

Brown BE, Dunne RP, Goodson MS, Douglas AE (2000) Bleaching patterns in reef corals. Nature 404:142-143

Buerger P, Schmidt GM, Wall M, Held C, Richter C (2015) Temperature tolerance of the coral Porites lutea exposed to simulated large amplitude internal waves (LAIW). J Exp Mar Bio Ecol 471:232-239

Clarke KR, Warwick RM (2001) Changes in marine communities: an approach to statistical analysis and interpretation, 2nd edn. PRIMER-E Ltd, Plymouth, UK

Connolly SR, Lopez-Yglesias MA, Anthony KR (2012) Food availability promotes rapid recovery from thermal stress in a scleractinian coral. Coral Reefs 31:951-960

Ezzat L, Towle E, Irisson JO, Langdon C, Ferrier-Pagès C (2015) The relationship between heterotrophic feeding and inorganic nutrient availability in the scleractinian coral T. reniformis under a short-term temperature increase. Limnol Oceanogr 61:89-102

Fabricius KE, Langdon C, Uthicke S, Humphrey C, Noonan S, De'ath G, Okazaki R, Muehllehner N, Glas MS, Lough JM (2011) Losers and winners in coral reefs acclimatized to elevated carbon dioxide concentrations. Nat Clim Chang 1:165-169

Finelli CM, Helmuth BST, Pentcheff ND, Wethey DS (2006) Water flow influences oxygen transport and photosynthetic efficiency in corals. Coral Reefs 25:47-57

Fitt WK, McFarland FK, Warner ME, Chilcoat GC (2000) Seasonal patterns of tissue biomass and densities of symbiotic dinoflagellates in reef corals and relation to coral bleaching. Limnol Oceanogr 45:677-685

Fitt WK, Gates RD, Hoegh-Guldberg O, Bythell JC, Jatkar A, Grottoli AG, Gomez M, Fisher P, Lajeunesse TC, Pantos O, Iglesias-Prieto R, Franklin DJ, Rodrigues LJ, Torregiani JM, van Woesik R, Lesser MP (2009) Response of two species of Indo-Pacific corals, Porites cylindrica and Stylophora pistillata, to short-term thermal stress: the host does matter in determining the tolerance of corals to bleaching. J Exp Mar Bio Ecol 373:102-110

Glynn PW (1996) Coral reef bleaching: facts, hypotheses and implications. Glob Chang Biol 2:495-509

Grottoli AG, Rodrigues LJ, Juarez C (2004) Lipids and stable carbon isotopes in two species of Hawaiian corals, Porites compressa and Montipora verrucosa, following a bleaching event. Mar Biol 145:621-631

Grottoli AG, Rodrigues LJ, Palardy JE (2006) Heterotrophic plasticity and resilience in bleached corals. Nature 440:1186-1189

Hoegh-Guldberg O, Salvat B (1995) Periodic mass-bleaching and elevated sea temperatures: bleaching of outer reef slope communities in Moorea, French Polynesia. Mar Ecol Prog Ser 121:181-190

Hoegh-Guldberg O, Jones RJ (1999) Photoinhibition and photoprotection in symbiotic dinoflagellates of reef-building corals. Mar Ecol Prog Ser 183:73-86 
Hoegh-Guldberg O, Mumby PJ, Hooten AJ, Steneck RS, Greenfield P, Gomez E, Harvell CD, Sale PF, Edwards AJ, Caldeira K, Knowlton N, Eakin CM, Iglesias-Prieto R, Muthiga N, Bradbury RH, Dubi A, Haziolos ME (2007) Coral reefs under rapid climate change and ocean acidification. Science 318:1737-1742

Jackson CR (2004) An atlas of internal solitary-like waves and their properties, 2nd edn. Office of Naval Research, Global Ocean Associates, Alexandria, VA

Jackson C (2007) Internal wave detection using the moderate resolution imaging spectroradiometer (MODIS). J Geophys Res. doi:10.1029/2007JC004220

Jantzen C, Schmidt GM, Wild C, Roder C, Khokiattiwong S, Richter C (2013) Benthic reef primary production in response to large amplitude internal waves at the Similan Islands (Andaman Sea, Thailand). PLos ONE 8:e81834. doi:10.1371/journal.pone.0081834

Jokiel PL (1978) Effects of water motion on reef corals. J Exp Mar Bio Ecol 35:87-97

Kohler KE, Gill SM (2006) Coral point count with excel extensions (CPCe): a visual basic program for the determination of coral and substrate coverage using random point count methodology. Comput Geosci 32:1259-1269

LaJeunesse TC, Pettay DT, Sampayo EM, Phongsuwan N, Brown B, Obuta DO, Hoegh-Guldberg O, Fitt WK (2010) Long-standing environmental conditions, geographic isolation and host-symbiont specificity influence the relative ecological dominance and genetic diversification of coral endosymbionts in the genus Symbiodinium. J Biogeogr 37:785-800

Leichter JJ, Deane GB, Stokes MD (2005) Spatial and temporal variability of internal wave forcing on a coral reef. J Phys Oceanogr 35:1945-1962

Lesser MP (2006) Oxidative stress in marine environments: biochemistry and physiological ecology. Ann Rev Physiol 68:253-278

Lorenzen CJ (1967) Determination of chlorophyll and pheo-pigments: spectrophotometric equations. Limnol Oceanogr 12:343-346

Lowry OH, Rosebrough NJ, Farr AL, Randall RJ (1951) Protein measurement with the Folin phenol reagent. J Biol Chem 193:265-275

Loya Y, Sakai K, Yamazato K, Nakano Y, Sambali H, van Woesik R (2001) Coral bleaching: the winner and the losers. Ecol Lett 4:122-131

Mayfield AB, Fan TY, Chen CS (2013) Physiological acclimation to elevated temperature in a reef-building coral from an upwelling environment. Coral Reefs 32:909-921

McClanahan TR, Ateweberhan M, Muhando CA, Maina J, Mohammed MS (2007a) Effects of climate and seawater temperature variation on coral bleaching and mortality. Ecol Monogr 77:503-525

McClanahan TR, Ateweberhan M, Graham NAJ, Wilson SK, Sebastián C, Guillaume MMM, Bruggemann JH (2007b) Western Indian Ocean coral communities: bleaching responses and susceptibility to extinction. Mar Ecol Prog Ser 337:1-13

McCowan DM, Pratchett MS, Baird AH (2012) Bleaching susceptibility and mortality among corals with differing growth forms. Proc 12th Int Coral Reef Symp 9A:1-6

Middlebrook R, Hoegh-Guldberg O, Leggat W (2008) The effect of thermal history on the susceptibility of reef-building corals to thermal stress. J Exp Biol 211:1050-1056

Moya A, Tambutté S, Tambutté E, Zoccola D, Caminiti N, Allemand D (2006) Study of calcification during a daily cycle of the coral Stylophora pistillata: implications for 'light-enhanced calcification'. J Exp Biol 209:3413-3419

Muscatine L (1990) The role of symbiotic algae in carbon and energy flux in reef corals. In: Dubinsky Z (ed) Ecosystems of the world: coral reefs. Elsevier, Amsterdam, The Netherlands, pp 75-87

Nakamura T, van Woesik R (2001) Water-flow rates and passive diffusion partially explain differential survival of corals during the 1998 bleaching event. Mar Ecol Prog Ser 212:301-304
Oksanen J, Blanchet FG, Kindt R, Legendre P, Minchin PR, O‘Hara RB, Simpson GL, Solymos P, Stevens MHH, Wagner H (2013) vegan: Community Ecology Package. R package version 2.0-9. http://CRAN.R-project.org/package=vegan

Oliver TA, Palumbi SR (2011) Do fluctuating temperature environments elevate coral thermal tolerance? Coral Reefs 30:429-440

Osborne AR, Burch TL (1980) Internal solitons in the Andaman Sea. Science 208:457-460

Phongsuwan N, Chansang H (2012) Repeated coral bleaching in the Andaman Sea, Thailand, during the last two decades. Phuket Marine Biological Center Research Bulletin 71:19-41

Putnam HM, Edmunds PJ, Fan TY (2010) Effect of a fluctuating thermal regime on adult and larval reef corals. Invert Biol 121:199-209

Core Team R (2014) R: a language and environment for statistical computing. R Foundation for Statistical Computing, Vienna, Austria

Riegl B, Branch GM (1995) Effects of sediment on the energy budgets of four scleractinian (Bourne 1900) and five alcyonacean (Lamouroux 1816) corals. J Exp Mar Bio Ecol 186:259-275

Riegl B, Piller WE (2003) Possible refugia for reefs in times of environmental stress. Int J Earth Sci 92:520-531

Roder C, Fillinger L, Jantzen C, Schmidt GM, Khokiattiwong S, Richter C (2010) Trophic response of corals to large amplitude internal waves. Mar Ecol Prog Ser 412:113-128

Roder C, Jantzen C, Schmidt GM, Kattner G, Phongsuwan N, Richter C (2011) Metabolic plasticity of the corals Porites lutea and Diploastrea heliopora exposed to large amplitude internal waves. Coral Reefs 30:57-69

Saxby T, Dennison WC, Hoegh-Guldberg O (2003) Photosynthetic response of the coral Montipora digitata to cold temperature stress. Mar Ecol Prog Ser 248:85-97

Schmidt GM, Phongsuwan N, Jantzen C, Roder C, Khokiattiwong S, Richter C (2012) Coral community composition and reef development at the Similan Islands, Andaman Sea, in response to strong environmental variations. Mar Ecol Prog Ser 456:113-126

Schreiber U (2004) Pulse-amplitude-modulation (PAM) fluorometry and saturation pulse method: an overview. In: Papageorgiou GC, Govindgee (eds) Advances in photosynthesis and respiration vol. 19. Chlorophyll a fluorescence: a signature of photosynthesis. Springer, The Netherlands, pp 279-319

Sheppard C (2009) Large temperature plunges recorded by data loggers at different depths on an Indian Ocean atoll: comparison with satellite data and relevance to coral refuges. Coral Reefs 28:399-403

Storlazzi CD, Field ME, Cheriton OM, Presto MK, Logan JB (2013) Rapid fluctuations in flow and water-column properties in Asan Bay, Guam: implications for selective resilience of coral reefs in warming seas. Coral Reefs 32:949-961

Strickland JDH, Parsons TR (1972) A practical handbook of seawater analysis. Bulletin 167, 2nd edition, Fisheries Research Board of Canada, Ottawa

van Hooidonk R, Maynard JA, Planes S (2013) Temporary refugia for coral reefs in a warming world. Nat Clim Chang 3:508-511

Vlasenko V, Stashchuk N (2007) Three-dimensional shoaling of large-amplitude internal waves. J Geophys Res. doi:10.1029/ 2007JC004107

Wall M, Schmidt GM, Janjang P, Khokiattiwong S, Richter C (2012) Differential impact of monsoon and large amplitude internal waves on coral reef development in the Andaman Sea. PLoS One 7:e50207

Wall M, Putchim L, Schmidt GM, Jantzen C, Khokiattiwong S, Richter C (2014) Large amplitude internal waves benefit corals during thermal stress. Proc Roy Soc Lond B Biol Sci 282:20140650 